\title{
Correlation Pattern of oxLDL, cortisol, hsCRP, and Adiponectin Levels in Atherosclerosis Risk Population-Based on Framingham Risk Score
}

\author{
Kumboyono Kumboyono ${ }^{1}$, Indah Nur Chomsy ${ }^{2}$, Fitria Nugraha Aini ${ }^{3}$, Titin Andri Wihastuti ${ }^{1, *}$
}

Kumboyono Kumboyono', Indah Nur Chomsy' ${ }^{2}$, Fitria Nugraha Aini ${ }^{3}$, Titin Andri Wihastuti ${ }^{1, *}$

'School of Nursing, Faculty of Medicine, University of Brawijaya, Malang, 65145, INDONESIA

${ }^{2}$ Doctoral Program of Medical Science, Faculty of Medicine, University of Brawijaya, Malang, 65145, INDONESIA

${ }^{3}$ Faculty of Medicine, University of Islam

Malang, Malang, INDONESIA

\section{Correspondence}

\section{Titin Andri Wihastuti}

School of Nursing, Faculty of Medicine, University of Brawijaya, Malang, 65145, INDONESIA

E-mail: titinwihastuti@gmail.com

History

- Submission Date: 29-09-2021;

- Review completed: 23-10-2021;

- Accepted Date: 02-11-2021.

DOI : 10.5530/pj.2022.14.3

Article Available online http://www.phcogj.com/v14/i1

\section{Copyright}

(C) 2022 Phcogj.Com. This is an openaccess article distributed under the terms of the Creative Commons Attribution 4.0 International license.

\begin{abstract}
Background: The central pathology of cardiovascular disease (CVD) is atherosclerosis. Therefore, it is necessary to examine proteins involved in the and CVD disease mechanism to predict the occurrence of cardiovascular disease due to atherosclerosis. Purpose: This study analysed the correlation pattern of hsCRP, oxLDL, cortisol, and adiponectin levels in atherosclerotic risk population based on the Framingham Risk Score (FRS) to determine the risk of atherosclerosis. Methods Participants were selected using the purposive sampling method,158 participants classes were fired into three risk groups according to FRS. Blood samples were collected, a hsCRP, oxLDL, cortisol, and adiponectin levels were measured using Enzyme-linked Immunosorbent Assay (ELISA). Results and Discussion: Using the inner model test result, four significant direct relationships are formed, indicated by $p$-value $<0.000$. It was FRS to oxLDL, cortisol adiponectin, cortisol to oxLDL, and oxLDL to adiponectin. Based on the indirect effect analysis, it is known that the indirect effect of FRS on Adiponectin through the increase in hs-CRP levels (0.211), FRS on Adiponectin increases in OxLDL levels is significant (-0.224). The coefficient of the effect of the FRS on Adiponectin levels through an increase in OxLDL levels is negative, and also FRS on Adiponectin. The indirect effect of FRS on Adiponectin is that the indirect effect and is not significant (4.083) through the increase in cortisol levels. Conclusion: All variables used in this study are correlated with each other. FRS with hsCRP and adiponectin form a relationship that directly affects each other. Meanwhile, FRS affect adiponectin through OxLDL and cortisol.

Key words: Adiponectin, Atherosclerosis, Cardiovascular disease, Framingham Risk Factor, hsCRP
\end{abstract}

\section{INTRODUCTION}

Cardiovascular disease is a severe global health problem and has become a significant cause of death in developed and developing countries. The World Health Organization (WHO) states that around 17.9 million people died from cardiovascular disease in 2016 , representing $31 \%$ of the total deaths worldwide. Eighty-five per cent of these deaths are due to heart attacks and strokes. ${ }^{1}$ In Indonesia, deaths from cardiovascular disease reached 259,738 people or $15.45 \%$ of the total deaths. ${ }^{1}$ Furthermore, it is estimated that by 2030 , deaths due to cardiovascular disease will increase to 23.6 million. $^{2}$

The primary pathology that causes cardiovascular disease is atherosclerosis. ${ }^{3}$ Atherosclerosis is a chronic inflammatory disease characterised accumulation of cholesterol or plaque on the inner walls of arteries. ${ }^{4}$ The process of atherosclerosis begins with the formation of fatty streaks, which are accumulations of foam cells in the intima layer of arteries. Fatty streaks then evolve progressively into fibrous cap atheroma and then into atherosclerotic plaques. Atherosclerotic plaque is composed of inflammatory cells, smooth muscle cells, connective tissue and fat components. Furthermore, atherosclerotic plaques will develop into increasingly progressive lesions due to the inflammatory process and cause various complications. ${ }^{5-7}$

There are various risk factors for cardiovascular disease. Non-modifiable risk factors consist of age, gender and family history, and modifiable risk factors considered increased serum lipid levels, hypertension, smoking, diabetes mellitus, lack of physical activity, psychosocial stress, obesity and increased homocysteine levels. ${ }^{8-9}$ The risk of coronary heart disease due to atherosclerosis in the next ten years can be predicted in percentage terms using the Framingham Risk Score (FRS). Individuals with an FRS percentage of less than or equal to $10 \%$ have a low risk (low risk), with a percentage of $10-20 \%$ being an intermediate risk individual (intermediate risk). Individuals with a percentage above $20 \%$ have a high risk (high risk) for coronary heart disease (CHD). ${ }^{10}$ The Framingham Risk Score is a valid method and the most widely used and recommended by the American Heart Association (AHA) to predict the occurrence of cardiovascular disease due to atherosclerosis. ${ }^{11,12}$ However, the differences in the characteristics of individual risk factors in a condition influenced by differences in race, ethnicity, culture, and geography make researchers interested in replicating this score in conditions of atherosclerosis risk in different regions.

In addition to the components used as benchmarks in calculating the risk of atherosclerosis in FRS, enzymes, proteins, hormones, or other biochemical markers in the body can influence the mechanism of atherogenesis. One example of a biomarker of atherosclerosis is Oxidized Low-Density Lipoprotein (OxLDL). The role of OxLDL in the formation of atherosclerotic plaques is by inducing endothelial cell dysfunction, smooth muscle cell migration and 
proliferation, formation of foam cell. ${ }^{13}$ Thus, OxLDL is a marker of atherosclerosis detected throughout the atherosclerosis stage and is associated with endothelial cell damage, inflammation and oxidative stress. ${ }^{14}$ As risk factors increase and the constant discomfort felt by people with atherosclerosis is one of the stress triggers. Stress can exacerbate CVD by altering the function of the hypothalamic-pituitaryadrenal (HPA) axis. ${ }^{15}$ The effect of alteration HPA is high levels of the hormone cortisol. As compensation for stress caused by the decreased quality of life of patients, cortisol is known to have an essential role in developing atherogenesis. Cortisol affects the regulation of vascular endothelial action, driving the differentiation of circulating monocytes into macrophages by regulating the production of inflammatory interleukins. ${ }^{16,17}$

Inflammation is often considered an essential trigger in several diseases. Considering the vital role played by the inflammatory process in the pathomechanism of atherosclerosis, it is necessary to examine several proteins involved in the mechanism of inflammation and CVD disease. ${ }^{18} \mathrm{C}$-reactive Protein (CRP) has been used to predict cardiovascular disease progression as a biomarker of inflammation. ${ }^{19}$ CRP was measured by a high-sensitivity test which became known as high-sensitivity-CRP (hsCRP). This hsCRP biomarker can also be used to identify high-risk groups for recurrent events in patients with atherosclerosis. ${ }^{20}$ Hepatocytes synthesise CRP protein in response to proinflammatory cytokines, particularly interleukin-6. CRP plays an essential role in many aspects of atherogenesis, including activation of the complement pathway, lipid uptake by macrophages, release of proinflammatory cytokines, inducing expression of tissue factors in monocytes, promoting endothelial dysfunction and inhibiting nitric oxide (NO) production. ${ }^{21,22}$

In addition, some proteins also play an essential role in the pathogenesis of atherosclerosis. This role makes the protein can be used as a biomarker of atherosclerosis, known as adiponectin. Adiponectin is secreted by adipose tissue and is known for its anti-diabetic, antiatherosclerosis, anti-inflammatory and anti-tumour functions, widely found in blood circulation..$^{23}$ The role of adiponectin as an antiinflammatory is by inhibiting the differentiation of myeloid progenitor cells, modulating macrophage function and decreasing the expression of Toll-like receptor 4 (TLR4), inhibiting the production of chemokines and proinflammatory cytokines (IL-6, TNF- $\alpha$ ) and upregulation of anti-inflammatory cytokine (IL-10) production in macrophages. ${ }^{24}$ In addition, adiponectin regulates the process of atherogenesis from the initiation phase to the development of atherosclerosis by modulating endothelial inflammation and direct anti-atherogenic effects on blood vessels. Furthermore, adiponectin modulates endothelial inflammation by inhibiting the production of proinflammatory cytokines in endothelial cells and reducing the expression of adhesion molecules VCAM-1, ICAM-1 and e-selectin. ${ }^{25}$

The risk grouping method based on FRS, combined with oxLDL, cortisol, hsCRP, and adiponectin levels as biomarkers in atherosclerosis that has been mentioned above, is still an exciting discussion and rarely studied. This complex problem is a causal relationship phenomenon that involves many variables. The pattern of the relationship between these variables is expected to be used to determine the risk factors that cause atherosclerosis. By knowing the risk of atherosclerosis early, cardiovascular disease can be prevented earlier.

\section{MATERIAL AND METHODS}

\section{Research design and population studies}

This study was a cross-sectional study that used a venous blood sample taken from the atherosclerosis risk population. The study aimed to analyse the correlation of hsCRP and adiponectin following FRS risk groups. The target population was selected based on atherosclerosis risk factors identified during the health campaign and medical checkup conducted in Malang, Indonesia. This research using purposive sampling method, in which every visitor who fulfilled the inclusion criteria was included in the study. The grouping was classified into three risk groups based on the score percentage: mild $(<10 \%)$, intermediate (10-20\%), and high $(>20 \%)$ risk group. This classification was conducted using MD Calc Medical Calculator \& Decision Support version 1.0.19 for Android. Risk factors measured were the age of $>30$ years, systolic blood pressure of $\geq 140 \mathrm{mmHg}$, history of smoking of more than a pack a day in one year, a total cholesterol level of $\geq 240 \mathrm{mg} / \mathrm{dL}$, HDL level of $\leq 40 \mathrm{mg} / \mathrm{dL}$, family history of cardiovascular disease, and obesity (BMI $\geq 23 \mathrm{~kg} / \mathrm{m}^{2}$ ).

\section{Measurement of oxLDL, cortisol, hsCRP, and adiponectin} levels

A complete blood count examination was carried out at the Central Laboratory of Saiful Anwar Hospital Malang, Indonesia. Analysis of blood samples was done to determine the concentration of hs-CRP and adiponectin using the Enzyme-linked Immunosorbent Assay (ELISAs) at the Biomedical Science Laboratory of Brawijaya University, according to the protocol from the manufacturer (Bioassay Technology Laboratory). Blood plasma was dissolved in the coating buffer (1:50). The diluted antigen was then added to the holes for $50 \mu \mathrm{L}$ in each hole. Incubation was carried out in dark conditions at $4^{\circ} \mathrm{C}$ overnight. The wells were incubated for three minutes, and the antigen was washed with $50 \mu \mathrm{L}$ PBS-Tween $200.05 \%$ three times. Subsequent incubation was done with $50 \mu \mathrm{L} 2 \%$ PBS-BSA as buffer coating for each well for 2 hours at room temperature. The buffer coating was then removed and washed using PBS-Tween $200.05 \%$ three times. Then it was incubated for 3 minutes every time it was washed. The incubation of dilute primary antibodies in PBS-BSA 1\% (1: $200-1: 500)$ was done for 2 hours at room temperature. The primary antibody was washed with PBS-Tween $200.05 \%$ in $50 \mu \mathrm{L}$ wells three times for 3 minutes each. The secondary antibodies (each $50 \mu \mathrm{L}$ ) diluted in PBS-BSA 1\% (1: 1000 - 1: 2500) was then washed. Incubation of dilute Strepavidin-Horse Radish Peroxidase (SA-HRP) (1: 1000) was carried out for 40-60 minutes at room temperature, then washed. Incubation of BCIP/NBT was carried out for 30 minutes at room temperature. A reaction buffer stopped $3 \mathrm{M}$ $\mathrm{HCl}$ solution added to each well, then immediately measured at $450 \mathrm{~nm}$ using a Micropipette Reader.

\section{Ethical clearance}

This research design has met and approved by Ethics Committee of the Faculty of Medicine, University of Brawijaya, Malang, Indonesia with registration number: 242/EC/KEPK09/2019. Furthermore, all of the patients who participate in this study provided informed consent that has been accorded with the Declaration of Helsinki.

\section{Data Analysis}

Atherosclerosis risk group stratification in the sample population was measured using the Framingham Risk Score calculation with the MD Calc Medical Calculator \& Decision Support application version 1.0.19 for Android. The data needed in risk stratification are age, gender, history of smoking, total cholesterol, HDL, systolic blood pressure, history of hypertension treatment or not. We used Path Analysis with the help of software AMOS (Analysis of Moment Structures) version 6. The data is considered significant if $\mathrm{p}<0.05$. The test used in this study is the multivariate normality test, Mahalanobis distance (Md). Examination of multivariate outliers was performed using the Mahalanobis criteria at a level of $p<0.001$. In addition, the Goodness of Fit Model test was conducted to determine whether empirical data supported the hypothetical model, and the inner model test (structural model) was conducted to test the hypothesis by using the t-test (T-Statistic) on each path of direct influence partially. 


\section{RESULTS}

\section{Baseline Characteristics of Respondents}

In this study, we found that women has more significant percentage than men in the low-risk group. Meanwhile, for the intermediate and highrisk groups, the percentage of men was greater than that of women. Thus in the next 10 years, male has a higher risk of cardiovascular disease than women. Similarly, the recapitulation of the data in this study shows that the age range of 50-69 years in each risk group has the most significant percentage.

In the low risk and intermediate-risk groups, the percentage of respondents who did not smoke was more significant than those who smoked and has stopped smoking. In the high-risk group, the percentage of smoking was more significant than that of non-smokers than participants who had quit smoking. Among the low and medium risk groups, the proportion of respondents who regularly exercise is more significant than those who do not exercise regularly. We also found that the obesity group had the highest percentage in the low and medium risk groups. The highest group presentation was normal in the high-risk group, and the lowest group presentation was obesity II. In the systolic pressure grouping, all risk groups had the highest pressure of $140-179 \mathrm{mmHg}$. For total cholesterol, the highest risk percentage was $200-239 \mathrm{mg} / \mathrm{dL}$, while the other group had a high presentation at $<200$ $\mathrm{mg} / \mathrm{dL}$. In total HDL, the low risk and intermediate-risk groups had a high presentation at more than equal to $40 \mathrm{mg} / \mathrm{dL}$, while the high-risk groups were $<40 \mathrm{mg} / \mathrm{dL}$.

\section{The oxLDL, cortisol, hsCRP, and adiponectin levels}

Based on the analysis results, the lowest cortisol level was 0.05 , and the highest was 0.11 . Thus, the average cortisol level is 0.1092 with a standard deviation of 0.00459; the standard deviation is far below the average value, which means that the distribution of cortisol data to all respondents is minimal. The average OxLDL level was 0.0990431 $\mathrm{ng} / \mathrm{mL}$ with a standard deviation of 0.00010523 . Again, the standard deviation is far below the average value, which means that the spread of OxLDL data to 158 respondents is minimal or almost the same.

The average hsCRP level of 158 respondents was $0.0572 \mathrm{ng} / \mathrm{mL}$ with a standard deviation of 0.00243 . The standard deviation is far below the average value, which means that the spread of hsCRP data to 158 respondents is also very small or almost the same. Meanwhile, the lowest adiponectin level from 158 respondents was $0.15253 \mathrm{ng} / \mathrm{mL}$, and the highest was $0.24682 \mathrm{ng} / \mathrm{mL}$. The average adiponectin level was $0.1785 \mathrm{ng} / \mathrm{mL} \mathrm{ng} / \mathrm{mL}$ with a standard deviation of 0.01868 . Again, the standard deviation is below the average value, which means that the distribution of adiponectin data to 158 respondents is small or not much different (Table 1).

\section{Path Analysis Assumption Test}

The correlation pattern of FRS with hsCRP and Adiponectin levels in the atherosclerosis risk population in this study was analysed path analysis model. The paths defined in this model are based on previously known theories. Before conducting path analysis, the Path model's assumptions are tested, namely normality, outliers, and linearity. The assumption of multivariate normality was tested with AMOS 6 software. The test results showed that the data was not normally distributed. This is indicated by the critical ratio value of 2.362 . The critical value of Z-count for $10 \%$ is 2.85 because the absolute value of $\mathrm{CR}$ for multivariate is $2.362<2.85$, the assumption of multivariate normality is fulfilled.

To test the presence or absence of outliers, we conducted using the Mahalanobis distance (Md). Mahalanobis distance measures the proximity of the average data centre point to each observation point.
In this case, the point of observation is the questionnaire number of the respondent. Examination of multivariate outliers was performed using the Mahalanobis criteria at a level of $p<0.001$. Mahalanobis distance is evaluated using degrees of freedom for the number of parameters in the model used, which is $=37$, wherefrom the statistical table it is obtained $=24.07494$. If the Md of the observation point $>24.07494$, the rule of decision making is said to be an outlier, whereas if the Md of the observation point is $<24.07494$, then it is said that the observation point is not an outlier. From the Mahalanobis distance table (Appendix 1), it can be seen that the farthest observation point is the 66th respondent with a value of $\mathrm{Md}=23,039$. When compared with the value $=24.07494$, then the Md value of the 66th point $<24.07494$, it is concluded that all observation points are not outliers.

\section{Inner Model Test Results on Direct Effects}

Based on the test of the inner model test result, it is known that there are eight direct relationships of the five parameters used in this study (Table 2). The eight relationships formed are relationships with different significance from each other. Of the eight inner relationships of the model, four relationships are not significant, indicated by p-value $>$ 0.000. For example, the direct effect relationship formed by FRS to cortisol, FRS to hsCRP, FRS to adiponectin, and hsCRP to adiponectin showed no significant direct effect. At the same time, the other four relationships formed a significant direct effect ( $p$-value $<0.000$ ), namely the relationship between FRS to oxLDL, cortisol to adiponectin, cortisol to oxLDL, and oxLDL to adiponectin. Considering that the coefficient of inner weight on several variables is negative, namely on FRS to adiponectin cortisol to oxLDL, and hsCRP to adiponectin indicates that the relationship between the two is inversely proportional. The higher one variable will lower the other, or if the variable increases by one unit, the other variable will decrease by $<0.000$.

\section{Inner Model Testing on Indirect Effects}

In addition to testing the direct effect, in multivariate modelling, indirect effects are also known. The indirect effect results from the multiplication of 2 (two) direct effects (the multiplication used is the standardised weights.) The indirect effect is declared significant if the two direct effects that form it are significant. If one or both are not significant, the effect is directly not significant, as shown in Table 3.

Based on the indirect effect analysis, it is known that the indirect effect of FRS on Adiponectin through the increase in hs-CRP levels,

Table 1: The hsCRP and Adiponectin Levels Statistics.

\begin{tabular}{lcccc} 
Variable & Minimum & Maximum & Mean & $\begin{array}{c}\text { Std. } \\
\text { Deviation }\end{array}$ \\
\hline oxLDL $(\mathrm{ng} / \mathrm{mL})$ & 0.098 & 0.099 & 0.099 & 0.000 \\
Cortisol $(\mathrm{ng} / \mathrm{mL})$ & 0.050 & 0.110 & 0.109 & 0.005 \\
hsCRP $(\mathrm{ng} / \mathrm{mL})$ & 0.051 & 0.061 & 0.057 & 0.002 \\
Adiponectin $(\mathrm{ng} / \mathrm{mL})$ & 0.153 & 0.246 & 0.178 & 0.009
\end{tabular}

Table 2: The results of the Inner Model Test on Direct Effects.

$\begin{array}{lcccc}\begin{array}{l}\text { Correlation of } \\ \text { variables }\end{array} & \text { Coefficient } & \text { SE } & \text { CR } & \text { p-value } \\ \text { FRS } \rightarrow \text { oxLDL } & 0.00 & 0.00 & -5.364 & 0.000 \\ \text { FRS } \rightarrow \text { Cortisol } & 0.001 & 0.00 & 1.396 & 0.163 \\ \text { FRS } \rightarrow \text { hsCRP } & 0.00 & 0.00 & -1.189 & 0.235 \\ \text { FRS } \rightarrow \text { Adiponectin } & -0.001 & 0.001 & -1.102 & 0.271 \\ \text { Cortisol } \rightarrow \text { Adiponectin } & 152.497 & 20.08 & 7.594 & 0.000 \\ \text { Cortisol } \rightarrow \text { OxLDL } & -1.666 & 0.003 & -555.418 & 0.000 \\ \text { OxLDL } \rightarrow \text { Adiponectin } & 93.023 & 12.01 & 7.745 & 0.000 \\ \text { hsCRP } \rightarrow \text { Adiponectin } & -0.964 & 0.526 & -1.831 & 0.067\end{array}$


Table 3: The results of the Inner Model Test on Indirect Effects.

$\begin{array}{ccc}\text { Correlation } & \text { Coefficient } & \text { Results } \\ \text { FRS } \rightarrow \text { HsCRP } \rightarrow \text { Adiponectin } & 0.021 & \text { FRS } \rightarrow \text { HsCRP (Not Sig.), HsCRP } \rightarrow \text { Adiponectin (Not Sig.) } \\ \text { FRS } \rightarrow \text { OxLDL } \rightarrow \text { Adiponectin } & -0.224 & \text { FRS } \rightarrow \text { OxLDL (Sig), OxLDL } \rightarrow \text { Adiponectin (Sig.) } \\ \text { FRS } \rightarrow \text { Cortisol } \rightarrow \text { Adiponectin } & 4.083 & \text { FRS } \rightarrow \text { Cortisol (Not Sig), Kortisol } \rightarrow \text { Adiponectin (Sig.) } \\ \text { Cortisol } \rightarrow \text { OxLDL } \rightarrow \text { Adiponectin } & -37.381 & \text { Cortisol } \rightarrow \text { OxLDL (Sig), OxLDL } \rightarrow \text { Adiponectin (Sig.) }\end{array}$

the indirect effect coefficient is 0.0211 and is not significant. Therefore, this value means that HsCRP cannot mediate the relationship of FRS to Adiponectin. The indirect effect of FRS on Adiponectin increases in OxLDL levels. The indirect effect coefficient is -0.224 and is significant. It means that OxLDL can mediate the relationship of FRS to Adiponectin. The coefficient of the effect of the Framingham Score on Adiponectin levels through an increase in OxLDL levels is negative; a negative coefficient means that if FRS increases, adiponectin will decrease through increasing OxLDL levels. The indirect effect of FRS on Adiponectin is that the indirect effect coefficient is 4.083 and is not significant through the increase in cortisol levels. It means that cortisol cannot mediate the relationship of FRS to Adiponectin.

FRS Correlation Pattern on oxLDL, cortisol, hsCRP, and adiponectin

In the direct effect table (Table 2), it is known that there is a relationship between the five parameters, and it can also be seen that the direct effect of the Framingham Score on cortisol, hsCRP and Adiponectin levels has no significant effect. Finally, Table 3 presents the indirect effect, which can be seen that the effect of the Framingham Score on Adiponectin levels through increasing levels of HsCRP and Adiponectin pathways is not significant. In contrast, the effect of Framingham Score on Adiponectin levels through increasing OxLDL levels is significant. It means that OxLDL is an excellent intermediary variable in mediating the effect of the Framingham Score on Adiponectin levels (Figure 1).

Based on Figure 1, it is known that the effect of FRS on adiponectin levels through HsCRP is not significant. The direct relationship between FRS and HsCRP is not significant; the relationship between hs-CRP and adiponectin is not significant (Figure 1 marked with red arrows). Otherwise, the effect of FRS on adiponectin levels through OxLDL is significant because the relationship between FRS and OxLDL is directly significant. The relationship between OxLDL and Adiponectin is also significant (Figure 1 marked with blue arrows). The coefficient of -0.22429 is negative, which means if FRS increases by one unit, adiponectin will decrease by 0.224929 by increasing one unit in OxLDL levels. The effect of FRS on Adiponectin levels through cortisol was not significant because the direct relationship between FRS and Cortisol was not significant (Figure 1 marked with red arrows). However, the direct relationship of cortisol with adiponectin was significant (Figure 1 marked with blue arrows).

\section{DISCUSSION}

Oxidized LDL (OxLDL) is a biomarker of oxidative stress conditions. These biomarkers play an essential role in the initiation and progression of atherosclerosis, which is the main pathomechanism of cardiovascular disease. ${ }^{26}$ OxLDL is involved in all stages of atherosclerosis, from initiating the fat streak to the development of instability and rupture of atherosclerotic plaques. In addition, OxLDL induces foam cell formation, downregulates endothelial NOS, increases matrix metalloproteinase formation, and induces apoptosis in human coronary endothelial cells. ${ }^{20}$

In this study, a direct effect was tested between FRS and OxLDL levels. So that, it is known that there is a significant direct effect between FRS on OxLDL. The relationship between the two is inversely proportional, meaning that the higher the FRS, the lower the OxLDL. The results of

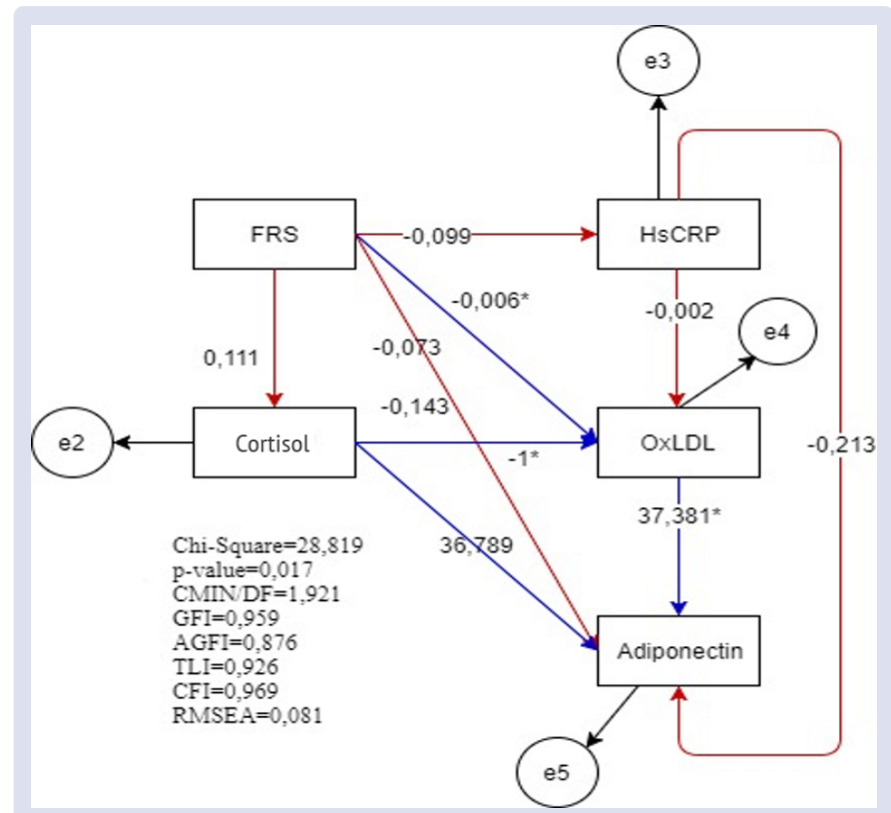

Figure 1: Corelation pattern of FRS to Adiponectin via hsCRP, OxLDL and Cortisol.

this study are following research by Reddy et al. conducted on 227 people aged 30-80 years in India. Reddy et al. stated that there was a significant correlation between FRS and oxLDL levels. ${ }^{27}$ The study concluded that oxLDL is a significant biomarker for predicting individuals $>40$ years of age to diagnose cardiovascular disease risk. A high Framingham score is associated with a higher prevalence of elevated oxLDL levels. In addition, there is also a higher prevalence of both forms of noncoronary cardiovascular disease and coronary heart disease. ${ }^{28}$

Cortisol is a hormone synthesised of cholesterol. Cortisol is the primary glucocorticoid component in the zona fasciculate of the adrenal cortex. Cortisol secretion responds to biochemical stress by suppressing the hypothalamic-pituitary-adrenal (HPA) axis. ${ }^{29-31}$ Stress caused by risk factors for atherosclerosis can trigger chronic stress. The stress was associated with an increase in smoking behaviour and Body Mass Index (BMI) levels, which would ultimately lead to increased inflammatory responses, such as C-reactive protein (CRP) and IL-6, cortisol levels, and central accumulation of body fat. Chronic stress occurs when stress stimuli are repeated continuously, resulting in cortisol circulating in the body maintained at higher-than-normal levels and over a long period..$^{32}$ Although not many studies have shown the relationship of cortisol to the risk of atherosclerosis, the role of cortisol is quite significant in developing atherosclerosis, regulating vascular endothelial action, driving the differentiation of circulating monocytes into macrophages by regulating the production of inflammatory interleukins. ${ }^{16,17}$ Therefore, cortisol can be used as a complementary parameter in the exploration of biomarkers to detect early atherosclerosis, which is associated with stress associated with increased risk factors. Based on this research, it is known that the direct effect of cortisol on adiponectin levels has a significant effect on the positive regression coefficient. In addition, the indirect effect of cortisol has also been proposed. It can be seen that the effect of Cortisol on Adiponectin levels through the 
increase in the OxLDL pathway is significant. It suggests that cortisol has a role related to atherosclerosis via adiponectin.

High sensitivity C-Reactive protein is one of the biomarkers of acute inflammation sensitive to predicting cardiovascular disease risk. ${ }^{19}$ Hs-CRP is a sensitive acute-phase protein that directly induces atherogenesis by disrupting endothelial function. In epidemiological studies, increased levels of hs-CRP were associated with an increased risk of developing coronary heart disease in the next ten years. ${ }^{33}$ CRP can be directly involved in every phase of atherosclerosis, such as through complement activation, apoptosis, vascular cell activation, monocyte recruitment, lipid accumulation and thrombosis. CRP is one of the substances presents in atherosclerotic lesions, predominantly localised vascular intima along with monocytes, macrophages, and lipoproteins. ${ }^{21}$

In this study, the direct effect of FRS on hsCRP was tested. As a result, it was found that there was no significant direct effect between FRS on hsCRP. Other studies have also not found a significant relationship between circulating levels of hsCRP and FRS. ${ }^{33}$ Consistent with this study, a study conducted by Alissa et al. (2006) also could not show a positive relationship between FRS and hs-CRP in Saudi men. In contrast to the research conducted by Albert et al., CRP levels are significantly correlated with FRS in Caucasian populations. ${ }^{34}$ Therefore, they have been used as an additional indicator for global CVD risk prediction. The hs-CRP levels appear to be correlated with mortality from cardiovascular disease, despite differences in ethnicity and stage of disease control. ${ }^{35}$

The Framingham Risk Score used as a non-invasive screening tool to measure cardiovascular disease risk in clinical practice and public health research. However, the predictive ability of FRS varies between populations, ethnic groups, and socioeconomic status. These insignificant results may explain the difference in the correlation between hs-CRP and FRS levels in our study. The addition of hsCRP levels to FRS resulted in mild improvement in risk factor discrimination and reclassification due to the high correlation of hsCRP with pre-existing risk factors. The long-term predictive capacity of hsCRP is likely to reflect the inflammatory process associated with atherosclerotic risk. ${ }^{19}$

Low adiponectin levels correlated positively with various disease states, including obesity, diabetes, and atherosclerosis. ${ }^{24,36}$ In addition, increased plasma adiponectin levels are predictors of reduced risk of coronary heart disease. ${ }^{37}$ Adiponectin functions as an anti-CHD protein by increasing fatty acid oxidation and increasing insulin sensitivity. In the vascular endothelium, adiponectin reduces the number of monocytes that adhere to the endothelium, suppresses the transformation of macrophages into foam cells, and inhibits vascular smooth muscle cells. ${ }^{23}$

In this study, it was concluded that there was no significant correlation between FRS and Adiponectin. This conclusion is in line with the research conducted by Sohn et al. on 180 men with metabolic syndrome in South Korea. ${ }^{38}$ However, the insignificant results in this study may be because most of the respondents are obese. As previously explained, adiponectin increases fatty acid oxidation. In addition, it increases insulin sensitivity so that in obese people, it is possible to develop insulin resistance based on this theory that might cause the relationship between adiponectin and FRS to weaken.

In contrast to the conclusions in the Framingham Offspring Study (FOS). The study showed that low adiponectin levels were a significant independent risk factor for CHD in men. Whereas in the elderly, low adiponectin levels are a significant enough risk for CHD. Any intervention to increase adiponectin levels $>7.0 \mathrm{~g} / \mathrm{ml}$ can help prevent CHD occurrence. ${ }^{37}$

\section{CONCLUSION}

The five variables used in this study are correlated with each other. For example, FRS with hsCRP and adiponectin form a relationship that directly affects each other. Meanwhile, FRS affect adiponectin through OxLDL and cortisol. It suggests that risk factor relates to atherosclerosis via oxLDL, cortisol, hsCRP, and adiponectin.

\section{DATA AVAILABILITY}

The authors confirm that the data supporting the findings of this study are available within the article and its supplementary materials.

\section{ACKNOWLEDGEMENTS}

The author thanked the Indonesian Ministry of Education and Culture for facilitating the research.

\section{DISCLOSURE}

The author reports no conflicts of interest in this work.

\section{REFERENCES}

1. World Health Organization. Cardiovascular diseases (CVDs). Available from: http://www.who.int/mediacentre/factsheets/fs317/en/. 2017. Accessed 30.10.2018

2. Wihastuti TA, Sargowo D, Heriansyah T, et al. The reduction of aorta histopathological images by inhibiting reactive oxygen species (ROS) formation in hypercholesterolemia Rattus norvegicus treated with polysaccharide peptide (PSP) Ganoderma lucidum. Iran J Basic Med Sci. 2015;18:514-519.

3. Besler C, Lüscher TF, Landmesser U. Molecular mechanisms of vascular effects of High-density lipoprotein: alterations in cardiovascular disease. EMBO Mol Med. 2012;4(4):251-268.

4. Monalissa HW, Elya B, Puspitasari N. HMG-CoA Reductase Inhibitory Activity of Garcinia latissima Miq. Mesocarp Water Extract for Herbal Tea. Pharmacognosy Journal. 2018;10(6s):s141-s146.

5. Galkina E, Ley K. Immune and inflammatory mechanisms of atherosclerosis. Annu Rev Immunol. 2009;27:165-197.

6. Manduteanu I, Simionescu M. Inflammation in atherosclerosis: a cause or a result of vascular disorders? J Cell Mol Med. 2012;16(9):1978-1990.

7. Hansson GK, Libby P, Tabas I. Inflammation and plaque vulnerability. J Intern Med. 2015;278(5):483-493. doi:10.1111/joim.12406

8. Tabei SM, Senemar S, Saffari B, Ahmadi Z, Haqparast S. Nonmodifiable Factors of Coronary Artery Stenosis in Late Onset Patients with Coronary Artery Disease in Southern Iranian Population. J Cardiovasc Thorac Res. 2014;6(1):51-55. doi:10.5681/jcvtr.2014.010

9. Hajar R. Risk Factors for Coronary Artery Disease: Historical Perspectives. Heart Views. 2017;18(3):109-114.

10. Wilson PW. Lipids and vascular disease: a framingham perspective. Glob Heart. 2013;8(1):25-33.

11. Barroso LC, Muro EC, Herrera ND, Ochoa GF, Hueros JI, Buitrago F. Performance of the Framingham and SCORE cardiovascular risk prediction functions in a non-diabetic population of a Spanish health care centre: a validation study. Scand J Prim Health Care. 2010;28(4):242-248.

12. Maturana MA, Franz RF, Metzdorf M, da Silva TR, Spritzer PM. Subclinical cardiovascular disease in postmenopausal women with low/medium cardiovascular risk by the Framingham risk score. Maturitas. 2015;81(2):311-316.

13. Pirillo A, Norata GD, Catapano AL. LOX-1, OxLDL, and atherosclerosis. Mediators Inflamm. 2013;2013:152786. 
14. Ismawati, Mukhyarjon, Asni E, Romus I. The effect of alpha-lipoic acid on expression of VCAM-1 in type 2 diabetic rat. Anat Cell Biol. 2019;52(2):176-182.

15. Cohen S, Kessler RC, Gordon LU. Measuring stress: A guide for health and social scientists. Oxford University Press; USA: 1997

16. Fantidis $P$. The role of the stress-related anti-inflammatory hormones $\mathrm{ACTH}$ and cortisol in atherosclerosis. Curr Vasc Pharmacol 2010; 8: 517-525.

17. Yao BC, Meng LB, Hao ML, Zhang YM, Gong T, Guo ZG. Chronic stress: a critical risk factor for atherosclerosis. J Int Med Res. 2019;47(4):1429-1440.

18. Kumboyono K, Chomsy IN, Nurwidyaningtyas W, Cesa FY, Tjahjono CT, Wihastuti TA. Differences in senescence of late Endothelial Progenitor Cells in non-smokers and smokers. Tob Induc Dis. 2021;19:10.

19. Yousuf O, Mohanty BD, Martin SS, et al. High-sensitivity C-reactive protein and cardiovascular disease: a resolute belief or an elusive link?. J Am Coll Cardiol. 2013;62(5):397-408.

20. Koenig W. High-sensitivity C-reactive protein and atherosclerotic disease: from improved risk prediction to risk-guided therapy. Int J Cardiol. 2013;168(6):5126-5134

21. Shrivastava AK, Singh HV, Raizada A, Singh SK. C-reactive protein, inflammation and coronary heart disease. The Egyptian Heart Journal. 2015; 67: 89-97.

22. Kumboyono K, Nurwidyaningtyas W, Chomsy IN, Wihastuti TA. Early Detection of Negative Smoking Impacts: Vascular Adaptation Deviation Based on Quantification of Circulated Endothelial Activation Markers. Vasc Health Risk Manag. 2021;17:103-109.

23. Khandouzi M. Adiponectin and Atherosclerosis, IOSR Journal of Pharmacy and Biological Sciences. 2013.

24. Ouchi N, Walsh K. Adiponectin as an anti-inflammatory factor. Clin Chim Acta. 2007;380(1-2):24-30.

25. Ouedraogo R, Gong Y, Berzins B, et al. Adiponectin deficiency increases leukocyte-endothelium interactions via upregulation of endothelial cell adhesion molecules in vivo. J Clin Invest. 2007;117(6):1718-1726.

26. Liguori I, Russo G, Curcio F, et al. Oxidative stress, aging, and diseases. Clin Interv Aging. 2018;13:757-772.
27. Reddy RK, Mahendra J, Gurumurthy P, Jayamathi, Babu S Identification of Predictable Biomarkers in Conjunction to Framingham Risk Score to Predict the Risk for Cardiovascular disease (CVD) in Non Cardiac Subjects. J Clin Diagn Res. 2015;9(2):BC23-BC27.

28. Holvoet P, Mertens A, Verhamme P, Bogaerts K, Beyens G, et al. Circulating oxidizoxidiseds a useful marker for identifying patients with coronary artery disease. Arterioscler Thromb Vasc Biol. 2001; 21:844-848

29. Oswald LM, Zandi P, Nestadt G, Potash JB, Kalaydjian AE Wand GS. Relationship between cortisol response to stress and personality. Neuropsychopharmacology. 2006;31:1583-1591.

30. Staab CA, Maser E. 11ß-Hydroxysteroid dehydrogenase type 1 is an important regulator at the interface of obesity and inflammation. J Steroid Biochem Mol Biol. 2010;119:56-72.

31. Juster RP, McEwen BS, Lupien SJ. Allostatic load biomarkers of chronic stress and impact on health and cognition. Neurosci Biobehav Rev. 2010;35:2-16.

32. Lee DY, Kim E, \& Choi MH. Technical and clinical aspects of cortisol as a biochemical marker of chronic stress. BMB reports. 2015; 48(4): 209-216.

33. Musunuru K, Kral BG, Blumenthal RS, et al. The use of highsensitivity assays for $\mathrm{C}$-reactive protein in clinical practice. Nat Clin Pract Cardiovasc Med. 2008;5(10):621-635.

34. Albert MA, Glynn RJ, Ridker PM. Plasma concentration of C-reactive protein and the calculated Framingham Coronary Heart Disease Risk Score. Circulation. 2003;108(2):161-165.

35. Fonseca FA, Izar MC. High-Sensitivity C-Reactive Protein and Cardiovascular Disease Across Countries and Ethnicities. Clinics (Sao Paulo). 2016;71(4):235-242

36. Yanai H, Yoshida H. Beneficial Effects of Adiponectin on Glucose and Lipid Metabolism and Atherosclerotic Progression: Mechanisms and Perspectives. Int J Mol Sci. 2019;20(5):1190.

37. Ai M, Otokozawa S, Asztalos BF, et al.adiponectinn: an independent risk factor for coronary heart disease in men in the Framingham offspring Study. Atherosclerosis. 2011;217(2):543-548. doi:10.1016/j. atherosclerosis.2011.05.035

38. Sohn C, Kim J, Bae W. The framingham risk score, diet, and inflammatory markers in Korean men with metabolic syndrome. Nutr Res Pract. 2012;6(3):246-253. doi:10.4162/nrp.2012.6.3.246.

\section{GRAPHICAL ABSTRACT}

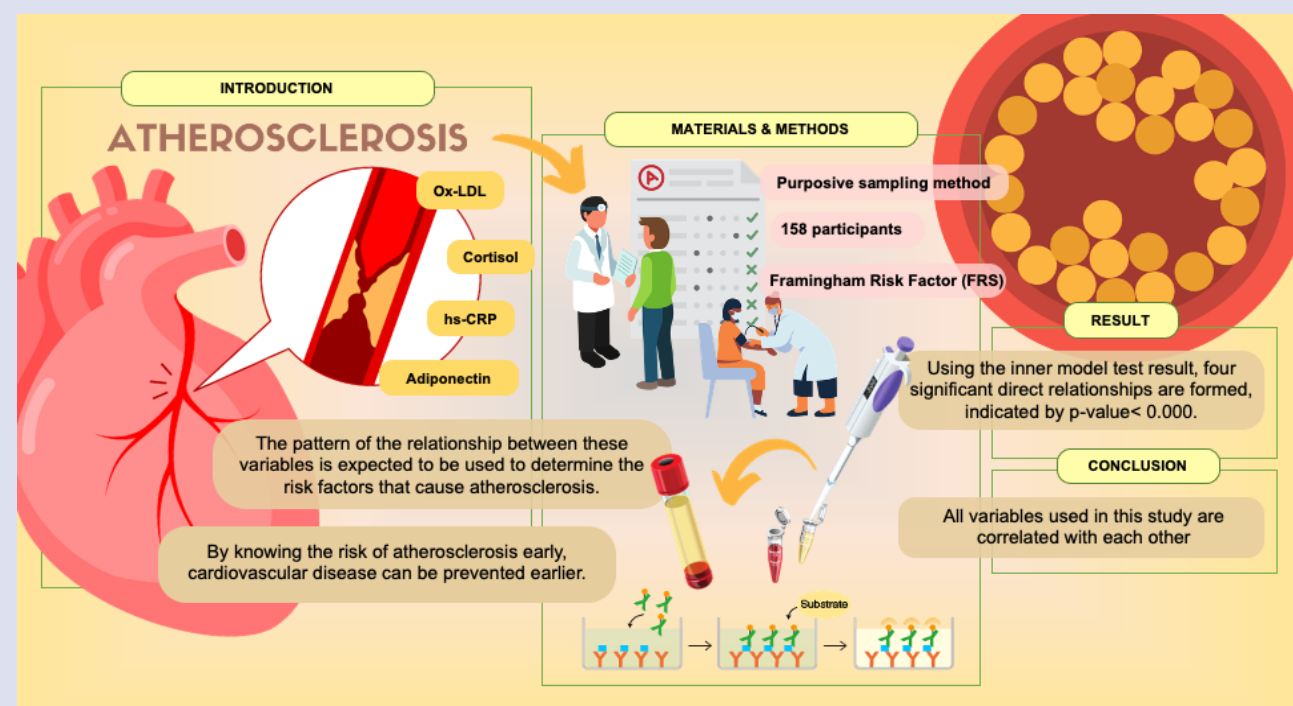




\section{ABOUT AUTHORS}

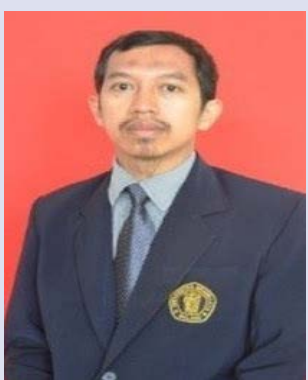

Dr. Ns. Kumboyono Kumboyono, S.Kep., M.Kep., Sp.Kom is a senior lecturer at the School of Nursing, University of Brawijaya. His research interest is in health promotion, prevention, and early diagnosis of disease.

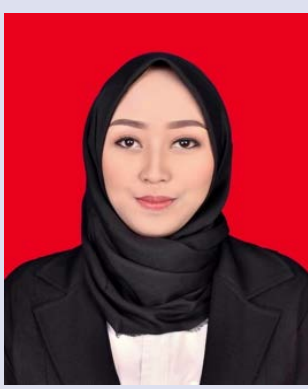

Indah Nur Chomsy, S.Si., M. Biomed is a doctoral student in Doctoral Program of Medical Science, University of Brawijaya. Her research is about cardiovascular disease, diabetic cardiomyopathy, metabolic syndrome; it's prevention, and pathophysiology.

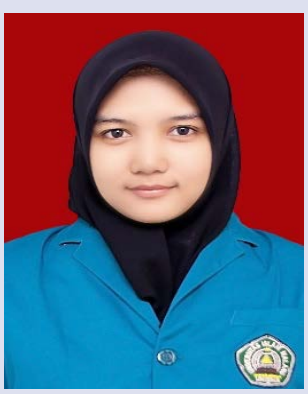

Fitria Nugraha Aini, MD, M.Biomed is a lecturer and researcher in the Medical Faculty of University of Islam Malang. Her research interest includes atherosclerosis, cardiovascular disease, and traditional herbal medicines.

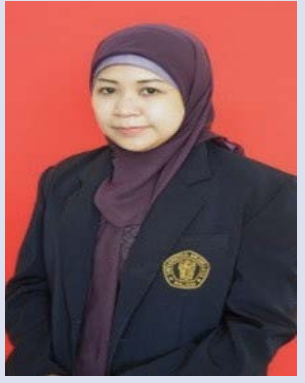

Prof. Dr. Titin Andri Wihastuti, S.Kp, M.Kes is a Professor in the Department of Basic Science in Nursing, School of Nursing, University of Brawijaya. Her research and teaching focus on biomedicine, cardiovascular health and pathology.

Cite this article: Kumboyono K, Chomsy IN, Aini FN, Wihastuti TA. Correlation Pattern of oxLDL, cortisol, hsCRP, and Adiponectin Levels in Atherosclerosis Risk Population-Based on Framingham Risk Score. Pharmacogn J. 2022;14(1): 14-20. 